\title{
The Treatment of Fear of Movement/(Re)injury in Chronic Low Back Pain: Further Evidence on the Effectiveness of Exposure In Vivo
}

\author{
*łJohan W. S. Vlaeyen, Ph.D., §Jeroen de Jong, M.Sc., ||Mario Geilen, P.T., \\ $\ddagger$ † Peter H. T. G. Heuts, M.D., and †Gerard van Breukelen, Ph.D. \\ *Department of Medical, Clinical, and Experimental Psychology and †Department of Methodology and Statistics, Maastricht \\ University, and the $\ddagger$ Pain Management and Research Center, University Hospital Maastricht, Maastricht; and §Institute for \\ Rehabilitation Research and \|Rehabilitation Center Hoensbroek, Hoensbroek, The Netherlands
}

Received July 18, 2001; revised December 3, 2001; accepted January $4,2002$.

Supported by grant 904-65-090 from the Council for Medical and Health Research of The Netherlands (MW-NWO).

Address correspondence and reprint requests to Dr. Johan W. S. Vlaeyen, Department of Medical, Clinical, and Experimental Psychology, Maastricht University, P. O. Box 616, NL 6200 MD Maastricht, The Netherlands; e-mail: j.vlaeyen@dep.unimaas.nl
The early notion that, in chronic patients, the lowered ability to accomplish tasks of daily living is merely the consequence of pain severity has now been reconsidered. Indeed, a steadily increasing number of studies are showing that observable physical performance and selfreported disability levels in subacute and chronic pain are associated with cognitive and behavioral aspects of 
pain rather than sensory and biomedical ones. ${ }^{1-5}$ Fearavoidance models have been proposed, and an increasing number of studies have successfully tested its major assumptions. ${ }^{4,6,7}$

A number of studies have reported that pain-related fear is one of the strongest predictors of variation in physical performance in terms of spinal isometric strength measured by the MedX (Ocala, FL, U.S.A.) lumbar extension machine, ${ }^{8}$ lifting capacity, ${ }^{4,9,10}$ and trunk and leg flexion and extension measured by the Cybex 350 system (Cybex International, Medway, U.S.A.). ${ }^{10,11}$ Avoidance of daily activities ultimately may result in functional disability ${ }^{10,12,13}$ and the socalled disuse syndrome, ${ }^{14}$ involving both physical deconditioning $^{15}$ and guarded movements. ${ }^{16}$ Avoidance also means the withdrawal from essential reinforcers, leading to mood disturbances such as irritability, frustration, and depression. Both depression and disuse are known to be associated with decreased pain tolerance level, ${ }^{17,18}$ and hence they may promote the painful experience.

Current therapies for excessive fears and anxiety are based on the experimental psychological work of Wolpe $^{19}$ on systematic desensitization. In this keystone treatment method, subjects progress through increasingly more-anxiety-provoking encounters with phobic stimuli, while using relaxation as a reciprocal inhibitor of rising anxiety. Because relaxation was intended to compete with the anxiety response, a graded format was chosen to keep anxiety levels as weak as possible. Later studies discovered that exposure to the feared stimuli appeared to be the most essential component of the systemic desensitization, and applied without relaxation, it produced comparable effects. ${ }^{20}$

In the area of chronic pain, Philips ${ }^{21}$ was one of the first to argue for the systematic application of exposure in vivo (EXP) to produce disconfirmations of expected consequences of physical activity (pain, reinjury). ${ }^{21}$ The actual applications were reported more recently. ${ }^{22,23} \mathrm{Al}-$ though EXP may appear quite similar to the usual graded activity (GA) programs, ${ }^{24,25}$ in that it gradually increases activity levels despite pain, they are both conceptually and practically quite different.

First, GA is based on instrumental learning principles, and selected health behaviors are shaped through positively reinforcing predefined quota of activities. ${ }^{26}$ Exposure in vivo, originally based on pavlovian conditioning in which associations among stimuli are being learned and anticipated ${ }^{27}$ (e.g., movement-severe pain), is currently viewed as a cognitive process during which fear is activated and catastrophic expectations are being challenged and disconfirmed, resulting in reductions of the threat value of the originally fearful stimuli. Second, during GA, special attention is drawn to the identification of positive reinforcers that can be provided when the individual quotas are met, whereas exposure pays special attention to the establishment of an individual hierarchy of the pain-related fear stimuli. Third, usual GA programs include individual exercises according to functional capacity and observed individual physical work demands, whereas EXP is individually tailored by including activities that are selected on the basis of the fear hierarchy and the idiosyncratic aspects of the fear stimuli.

Experimental support for the application of EXP is provided by Crombez et al. ${ }^{11}$ in their report on a sample of patients with chronic low back pain who were requested to perform four exercise trials at maximal force. As predicted, these patients initially overpredicted pain, but after repetition of the exercise trial the overprediction was readily corrected. In sum, it is quite plausible that, in analogy with the treatment of phobias, exposure to backstressing movements may indeed be a successful treatment approach for patients with back pain patients reporting substantial fear of movement/(re)injury. Indeed, using a replicated single-case experimental design, Vlaeyen et al. ${ }^{23,28}$ and de Jong et al. ${ }^{22}$ provided preliminary evidence that, for patients reporting fear of movement/(re)injury, a tailored EXP is superior to a nontreatment baseline period and a GA. Because the results were based on self-report only, the authors suggested to validate the assumption that the confrontation of feareliciting activities in the rehabilitation center is an analog for how patients respond in daily life situations by using ambulatory activity monitors in everyday life, outside the clinic.

The aim of the current study was to further test the effects of EXP in six patients with chronic low back pain reporting substantial fear of movement/(re)injury. With use of a replicated single-case crossover experimental design, EXP is contrasted with a usual GA program. In addition to self-report measures of pain-related fear, pain vigilance, pain intensity, and pain disability, an ambulatory activity monitor is used to examine whether treatment effects generalize to the home situation. A singlecase methodology was chosen as a flexible, logical, relatively fast, and still powerful way to evaluate clinical activity. $^{29}$

\section{MATERIALS AND METHODS}

\section{Study design}

A replicated crossover single-case (with alternating treatments) design was used with multiple measurements. Patients were randomly assigned to one of the two interventions contrasted. Randomization occurred after the 28 baseline days and was done by a computer system, providing allocations in a locked, unreadable file that could be assessed only by an independent research 
administrator. In treatment group $\mathrm{ABC}$, patients received EXP first, followed by GA. In treatment group ACB, the sequence of treatment modules was reversed. Two kinds of outcome measures were included: measures of pain catastrophizing, fear of pain, fear of movement/(re)injury, and pain intensity that were completed on a daily basis for 12 weeks; and measures of pain-related fear, pain vigilance, pain intensity, and pain disability that were determined during the initial screening, before and after baseline, directly after both treatment modes, and at the 12-month follow-up.

\section{Participants}

We included in the study six consecutive patients with nonspecific chronic low back pain who were referred for outpatient behavioral rehabilitation and who reported substantial fear of movement/(re)injury (Tampa scale for kinesophobia $[\mathrm{TSK}]^{30}$ score $\geq 40$, a cut-off based on the median of the TSK distribution of chronic low back pain samples reported earlier). Other inclusion criteria were nonspecific low back pain for 6 months or more and age of 18 to 65 years. Exclusion criteria were illiteracy, pregnancy, alcohol or drug abuse, and serious psychopathologic disorder. To check the latter, preset criteria based on Dutch norms were applied on the Symptom Checklist (SCL-90). ${ }^{31}$ On the basis of these criteria, two of the nine consecutive patients were excluded. For another patient, the protocol was discontinued after 3 weeks because of exacerbation of marital and concurrent depressive prob- lems. One patient did not respond to the invitation for the 12-month follow-up assessment.

The protocol was approved by our institutional ethics committee, and all patients gave written informed consent. Table 1 provides a brief summary of the characteristics of the patients who were included in this study.

\section{Procedure}

After undergoing a physical examination by the rehabilitation physician, patients received information about the study, along with an informed consent form and questionnaires (for TSK and SCL-90 data), which they needed to complete for inclusion in the study. When all criteria were met, patients were invited for a psychological intake procedure, during which a cognitive and behavioral analysis of the pain problem was made. The therapist also encouraged the patient to formulate specific treatment goals, preferably in terms of concrete activities that had been frequently avoided, such as the resumption of household chores, leisure activities, or work. A hierarchy of fear-eliciting movements and activities was made with use of the Photograph series of Daily Activities (PHODA). ${ }^{32}$

\section{Program overview}

All patients started with a baseline period (A) lasting 4 weeks, during which they completed daily measurements at home. Subsequently, two periods (B and C) of 4 weeks each followed, in which two treatments were

TABLE 1. Summary of the main characteristics of the patients

\begin{tabular}{|c|c|c|c|c|c|}
\hline Treatment & Sex & $\begin{array}{c}\text { Age } \\
\text { (years) }\end{array}$ & PD & PS & Most salient concern \\
\hline \multicolumn{6}{|l|}{$\overline{\mathrm{ABC}}$} \\
\hline Patient 2 & $\mathrm{~F}$ & 36 & 5 & No & $\begin{array}{l}\text { Persisting pain and increasing levels of disability made her believe that certain movements } \\
\text { caused "irreparable damage" in her back, possibly as a result of classical ballet exercises } \\
\text { during childhood. }\end{array}$ \\
\hline Patient 3 & $\mathrm{~F}$ & 41 & 7 & Yes & $\begin{array}{l}\text { After repeated surgeries for herniated disks and being advised to avoid activities that elicit } \\
\text { muscle spasms causing pain attacks, she believed that avoidance of activity is the best way } \\
\text { to protect herself from further damage. }\end{array}$ \\
\hline Patient 6 & M & 51 & 3 & No & $\begin{array}{l}\text { Believed that because of his heavy workload as a mechanic, his spine had "crumbled away." } \\
\text { He feared that certain movements (lifting, bending, and rotating) might "break" his spine } \\
\text { and that he could become paralyzed and wheelchair-bound. Also feared having undetected } \\
\text { cancer. }\end{array}$ \\
\hline \multicolumn{6}{|r|}{${ }^{\prime}$} \\
\hline Patient 1 & $\mathrm{~F}$ & 26 & 7 & Yes & $\begin{array}{l}\text { After surgery and the prescription of bed rest and a corset (due to an open vertebral arch, } \\
\text { disclosed by radiographs), she became fearful that certain movements could cause more } \\
\text { damage, with paralysis of the lower limbs as a serious risk. }\end{array}$ \\
\hline Patient 4 & $\mathrm{~F}$ & 46 & 3 & No & $\begin{array}{l}\text { She remembered pain onset vividly: felt sudden shooting pain while standing up after } \\
\text { mopping the floor on her knees. It reportedly felt as if her leg became "dead." She believed } \\
\text { that her leg was going to be paralyzed permanently and was still afraid that certain } \\
\text { movements would provoke similar pain attacks, possibly leading to paralysis of the leg. }\end{array}$ \\
\hline Patient 5 & $\mathrm{M}$ & 39 & 4 & No & $\begin{array}{l}\text { At pain onset, he heard a "crack" in his lower back while performing a simple reaching } \\
\text { movement, immediately followed by loss of control over his legs, and falling on the floor } \\
\text { with a "shooting" pain. Because he still felt these cracks, he feared that they might cause } \\
\text { paralysis of his legs and that he would end up in a wheelchair. }\end{array}$ \\
\hline
\end{tabular}

F, female; M, male; PD, pain duration (years); PS, prior surgeries. 
contrasted. The treatments were conducted during the first 3 weeks of each period. During week 4 of each period, the treatment was discontinued to give the patient an opportunity to practice his or her new skills in the home situation. Period B involved EXP, and in period C, a GA treatment was provided. Both treatments were imbedded in a comprehensive behavioral rehabilitation program following the operant treatment principles and including GA, pacing techniques, relaxation, and group education about ergonomics. ${ }^{33,34}$

\section{Exposure in vivo}

The first session of EXP always consists of unambiguously educating the patient in a way that the patient views pain as a common condition that can be selfmanaged, rather than as a serious disease or a condition that needs careful protection. Each patient is also given a careful explanation of the fear-avoidance model, with use of the patient's individual symptoms, beliefs, and behaviors. Subsequently, individually tailored practice tasks are developed on the basis of graded hierarchy of fear-eliciting situations. These take the form of a series of behavioral tests during which irrational expectations are explicitly being challenged. This involves asking patients to predict the occurrence of harm and repeating the same question after each exposure to that activity (for example, "How would you rate the probability that you may experience a severe pain attack after doing this activity?"). If the rating has decreased significantly, the therapist moves on to the next item of the hierarchy. Each movement or activity is modeled by the therapist, and patients are encouraged to engage in these fearful activities as much as possible until anxiety levels have decreased. $^{23,35}$

\section{Graded activity}

The GA is based on the operant treatment principles described by Fordyce. ${ }^{33,24}$ During the first week, baseline levels of activities are registered. The patients are asked to engage in activities until pain prevents them from continuing. Thereafter, activity quotas are agreed upon and the patient is requested to follow the quota according to a time-contingent fashion. A common exercise circuit consisting of several kinds of fitness equipment is provided.

There was only one restriction in the study. To avoid contamination with the EXP, activities that were placed above 50 on the fear-thermometer of the PHODA were excluded from the program. This was monitored by the physical therapist without notifying the patient about this rule. The rationale provided to the patients was that inactivity may lead to disuse, which often promotes pain, and that increasing muscle strength consequently is likely to prevent future disability.

\section{Measures}

\section{Credibility check}

At the end of the first session of each treatment module (when the rationale had been explained), patients rated three credibility items on three visual analog scales, with "not at all" and "very much" as the extremes: Do you expect that the program will help you to cope better with your pain complaints? Do you expect that the program will help patients with chronic back pain in general cope better with their pain complaints? Do you believe that the treatment offered to you is a meaningful treatment for patients with back pain? A credibility score was calculated as the mean of score on the three items. ${ }^{36}$

\section{Manipulation check}

To check whether the exposure indeed modified the fear appraisals, a short instrument was used, consisting of 11 visual analog scales (from 0 to 10) with items representing main factors of existing questionnaires for pain-related fear and catastrophizing (Table 2). This measure was administered on a daily basis during the whole duration of the study (84 days), except during the follow-up period. The patients were instructed to complete the scales each evening and to send the completed form the next day to the researchers by means of prestamped envelopes. Three main scores were derived, consisting of the mean scores (range, 0 to 10) of the items from the TSK, the Pain Anxiety Symptoms Scale, ${ }^{37}$ and the Pain Catastrophizing Scale. ${ }^{38}$ This measure has been shown to be sensitive to EXP in previous studies. ${ }^{22,23,28}$

TABLE 2. Items of the shortened and adapted versions of the TSK, PASS, and PCS that are completed on a daily basis

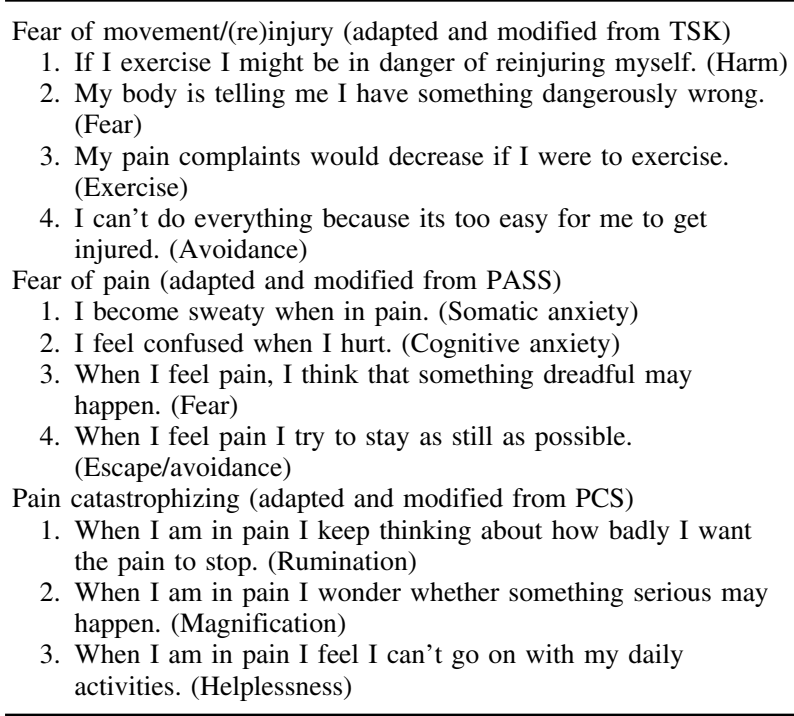

PASS, Pain Anxiety Symptoms Scale; PCS, Pain Catastrophizing Scale; TSK, Tampa Scale for Kinesiphobia. 


\section{Fear hierarchy}

A hierarchy of fear-eliciting movements and activities is made with use of the PHODA, ${ }^{32}$ which is a standardized method involving 98 photographs representing various physical daily-life activities such as lifting a child, mopping the floor, riding a bicycle, and lifting a crate from the trunk of a car. The patient is requested to place each photograph along a fear thermometer, consisting of a vertical line with 11 anchor points (ranging from 0 to 100), printed on a $60 \mathrm{~cm} \times 40 \mathrm{~cm}$ hardboard with this instruction: "Place each photograph on the thermometer according to the extent to which you feel that this movement is harmful to your back." After completion of the test, each photograph is given a rating according to the position on the thermometer. A total score ranging from 0 to 100 is calculated as the sum of each rating, divided by 9,800 (the maximum total score). The PHODA has been used successfully in previous studies. ${ }^{22,23,28}$

\section{Pain-related fear}

The Dutch version of the TSK was used. The TSK consists of 17 items, scored on a 4-point scale, measuring fear of (re)injury due to movement. ${ }^{30}$ Although factor analysis revealed four subscales (harm, fear of [re]injury, importance of exercise, and avoidance of activity) the total score has been recommended as the most valid and reliable measure. ${ }^{13}$ Total scores can range between 17 and 68. Reliability and validity of the Dutch version have been reported to be excellent. ${ }^{39}$

\section{Pain vigilance}

Vigilance for pain sensations was measured with the Pain Vigilance and Awareness Questionnaire (PVAQ). ${ }^{40}$ The Dutch version of the PVAQ has been reported to be reliable and valid. ${ }^{41}$

\section{Pain intensity}

One visual analog scale measuring present pain intensity was added to the 11 scales that were completed daily. The scale was anchored with "no pain at all" at one extreme and "worst pain experienced" at the other.

\section{Physical activity}

To objectively assess the level of physical activity in the natural environment of the patients, patients were requested to carry an ambulatory activity monitor (uniaxial accelerometer), attached to the belt dorsally, close to lumbar discs L4 and L5. Movement counts were registered for an entire week during daytime, except for activities involving contact with water (such as taking a shower and swimming). The patients kept track of carrying times and the kind of activities performed by means of a diary. At termination of the registration period, the patient returned the device and the data were downloaded onto a personal computer. Movement counts were added and subsequently divided by the time the accelerometer was carried. The activity monitor was carried three times for an entire week, week 4 of each period (A, B, and C). The output of activity monitors has been shown to validate measures of physical activity in the home environment. ${ }^{42}$

\section{Pain disability}

Patients also completed the Dutch version of the Roland Disability Questionnaire (RDQ) ${ }^{43}$ The RDQ is a 24-item two-point scale measuring the extent to which performance of daily activities is hampered by back pain, and it is one of the most widely used measures of disability in patients with back pain. Its reliability and validity are excellent. ${ }^{44}$

\section{Statistical analyses}

The following autoregressive time series model was fitted to the mean of the 3 patients in each condition by four outcome time series of the daily measures fear of movement/(re)injury, fear of pain, pain catastrophizing, and current pain intensity:

$$
Y_{t}=\beta_{0}+\beta_{1} X_{1}+\beta_{2} X_{2}+\beta_{3} T+\beta_{4} T_{1}+\beta_{5} T_{2}+e_{t}
$$

where $Y_{t}=$ the dependent variable at the $\mathrm{t}^{\text {th }}$ measurement $(\mathrm{t}=1,2, \ldots 84), \mathrm{X}_{1}=1$ in condition EXP and 0 else, $\mathrm{X}_{2}=1$ in condition GA and 0 else, $\mathrm{T}=$ measurement number $(\mathrm{T}=1,2, \ldots 84), \mathrm{T}_{1}=$ runs from -13.5 to +13.5 in condition EXP and is 0 else, $\mathrm{T}_{2}=$ runs from -13.5 to +13.5 in condition GA and is 0 else, and $e_{t}=$ residual at the $\mathrm{t}^{\text {th }}$ measurement, for which a first-order autoregressive model is assumed. That is, $e_{t}=\theta e_{t-1}+u_{t}$, where $\theta=$ first-order autocorrelation parameter $(-1<\theta$ $<+1)$ and $u_{t}=$ residual of the residual, and all $84 u_{t}$ values are independently normally distributed with mean 0 and unknown variance $\sigma^{2}$.

$\mathrm{T}$ is included to adjust for background trend. $\mathrm{T}_{1}$ and $\mathrm{T}_{2}$ are included to adjust for a change in trend due to treatment and are centered within the treatment period at hand to maintain the interpretation of $\mathrm{B}_{1}$ and $\mathrm{B}_{2}$ as the average difference between treatment (EXP or GA) and baseline period, adjusted for background trend. The residual $e_{t}$ is assumed to depend on the previous residual $\mathrm{e}_{\mathrm{t}-1}$ according to an autoregressive model, which is the most simple autoregressive integrated moving average model. Fitting the model with ordinary linear regression assumes that $\theta=0$, that is, the e-residuals are mutually independent. This is generally an incorrect assumption if the $\mathrm{N}(=84)$ observations are successive measurements of a time series instead of $\mathrm{N}$ distinct persons, thus leading to underestimation of standard errors, too-narrow confidence intervals, and type I errors for treatment effects. 
The model was fitted with the procedure AREG in SPSS-PC version 8.0 for Windows (SPSS, Chicago, U.S.A.). This procedure differs from ordinary regression in that it allows $\theta$ to be unequal to 0 and returns an estimate and test of $\theta$ as well as of each $\beta$-parameter. Model validity was checked by plotting the autocorrelation function and partial autocorrelation function of the $\mathrm{u}_{\mathrm{t}}$ values, which must be stationary and independent.

\section{A priori criteria for nondaily measures}

For PHODA, TSK, PVAQ, RDQ, and ambulatory activity monitor, the limited number of data made it impossible to use time series analysis. Therefore, we decided to formulate preset criteria to conclude whether the treatment could be considered successful. These criteria are based partly on existing norms. For the TSK and PVAQ, a reduction of more than 30 percentiles was considered relevant. For the RDQ, we concur with Stratford et al., ${ }^{45}$ who calculated that a change score of 5 can be considered clinically relevant. In the absence of any norms for PHODA, we estimated that a 50\% decrease would give us enough support that the threat value of the activities used in the EXP had decreased. For the ambulatory activity monitor, standardized z-scores were calculated for each patient individually by subtracting the mean number of baseline counts and dividing these values by the baseline standard deviation for that individual. This is done for mean counts in the week after the first and second treatment module. We estimated that an increase in three z-scores (equivalent to three standard deviations of the baseline counts) could be considered clinically relevant.

\section{RESULTS}

\section{Credibility check}

Credibility ratings were relatively high for both treatment modules (mean ratings of 8.6 and 8.7 on a visual

\section{Treatment group ABC}

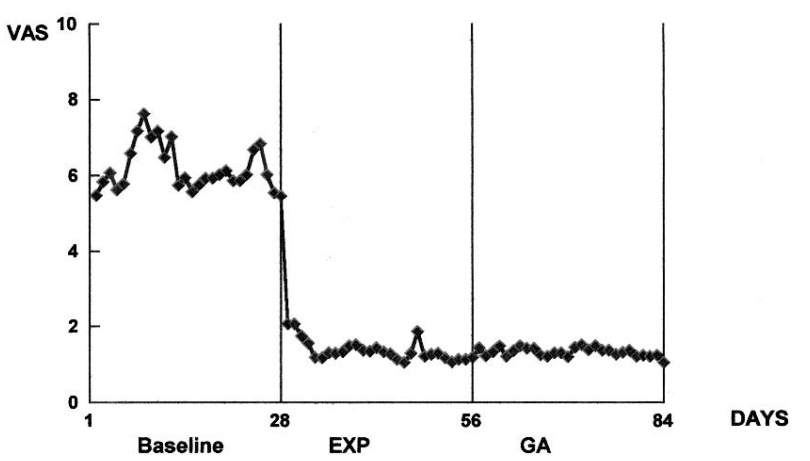

FIG. 1. Mean daily measures of fear of movement/(re)injury, across baseline $(A)$, exposure in vivo (EXP $[B])$, and graded activity (GA [C]) for treatment group $A B C$. VAS, visual analog scale score.

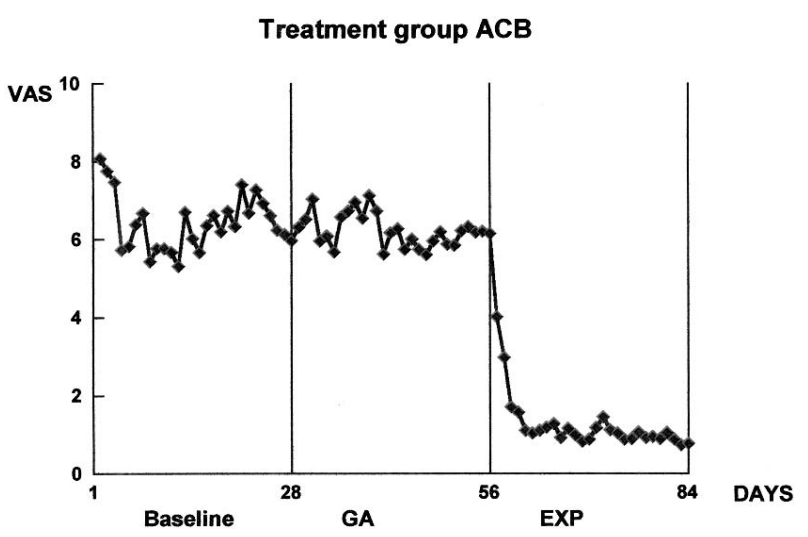

FIG. 2. Mean daily measures of fear of movement/(re)injury, across baseline $(A)$, exposure in vivo (EXP $[B])$, and graded activity (GA [C]) for treatment group $A C B$. VAS, visual analog scale score.

analog scale from 0 to 10 for GA and EXP, respectively), irrespective of the treatment order. This implies that the effectiveness of both treatments was not substantially influenced by differences in treatment credibility.

\section{Outcome measures}

Because the patterns of change of the patients within each condition were very similar, we decided to calculate means of the three time series. This produced more stable time series and reduced the number of statistical tests.

\section{Pain-related fear}

Figures 1 and 2 show the patterns of the mean daily visual analog scale ratings for fear of movement/(re)injury. In fact, the individual data very much resemble these averaged data. Visual inspection reveals that changes occur only when EXP follows either baseline or GA but not at the other transitions (baseline-GA, EXP-GA). This pattern suggests that pain-related fear is reduced only by the EXP. The results of the time series analysis according to the autoregressive procedure are displayed in Table 3 and appear to confirm these conclusions. After controlling for autocorrelation, overall trend, and trend within both treatment phases, we found significant changes only when EXP is introduced. In comparison with baseline, the EXP accounted for a mean decrease of $29.6 \%$ to $38.7 \%$ on the visual analog scales.

Table 4 shows that TSK scores decrease from a mean score of 46.5 (>80th percentile) to a mean score of 23.7 $(<10$ th percentile), but only when the EXP is delivered and not the GA. Similar results are found for PHODA, for which a drastic reduction is observed at the end of the EXP phase as compared with the baseline and start of EXP. A similar pattern is seen for pain vigilance. At the end of the GA for the patients who received GA, first PVAQ scores remain stable (mean score $=39 ;>80$ th percentile), whereas a mean of 26 and 17 (<10th percentile), 
TABLE 3 Results of AREG time series analysis. Adjusted differences (unstandardized $\beta$, ranging from 0 to 10 ) are displayed for comparisons between the baseline, exposure, and graded activity for the dependent variables fear of movement/(re)injury, fear of pain, pain catastrophizing, and current pain intensity, measured with a diary

\begin{tabular}{lcccc}
\hline & $\begin{array}{c}\text { Fear of } \\
\text { movement/ } \\
\text { (re)injury }\end{array}$ & $\begin{array}{c}\text { Fear } \\
\text { of pain }\end{array}$ & $\begin{array}{c}\text { Pain } \\
\text { catastrophizing }\end{array}$ & $\begin{array}{c}\text { Current } \\
\text { pain } \\
\text { intensity }\end{array}$ \\
\hline ABC & & & & \\
$\quad$ BAS-EXP & & & & \\
$\quad(\beta$ 1) & $-4.00 \ddagger$ & $-3.42 \ddagger$ & $-3.58 \ddagger$ & $-1.05^{*}$ \\
$\begin{array}{l}\text { BAS-GA } \\
(\beta \text { 2) }\end{array}$ & $-3.66 \ddagger$ & $-3.36 \dagger$ & $-2.41 \ddagger$ & 0.12 \\
$\begin{array}{l}\text { EXP-GA } \\
(\beta \text { 2- } \beta \text { 1) }\end{array}$ & 0.34 & -0.53 & 1.16 & $1.16^{*}$ \\
ACB \\
$\begin{array}{l}\text { BAS-GA } \\
(\beta \text { 2) }\end{array}$ \\
$\begin{array}{l}\text { BAS-EXP } \\
(\beta \text { 1) }\end{array}$ & 0.20 & $-0.69 *$ & 0.55 & -0.62 \\
$\begin{array}{l}\text { GA-EXP } \\
(\beta \text { 1- } \beta 2)\end{array}$ & $-3.71 *$ & $-4.11 \ddagger$ & $-2.34 \ddagger$ & $-4.74 \dagger$ \\
\hline
\end{tabular}

${ }^{*} p<0.05$.

$\dagger p<0.01$.

$\ddagger p<0.001$.

For current pain intensity in group $\mathrm{ABC}$ and pain catastrophizing in group ACB, an AR2 model was fitted to the data instead of an AR1 model, in view of the presence of a second-lag autocorrelation. For current pain intensity in group $\mathrm{ABC}$, a seasonal cycle of 6 was included in the model because of an additional sixth-lag autocorrelation.

AR, autoregressive; AREG, see Statistical Analyses section in text; BAS, baseline; EXP, exposure; GA, graded activity. respectively, is observed at the end of EXP. Notable is that all improvements remained during the follow-up period.

\section{Pain intensity}

Of interest, and quite unexpected, is that in treatment group ACB a significant reduction in pain intensity occurred during the EXP, as compared with baseline and GA. Further inspection revealed that this may be due to the effects of one patient in that condition who became almost pain-free after introduction of the EXP treatment. In treatment group $\mathrm{ABC}$, the data suggest that EXP resulted in a decrease in pain intensity, followed by a light increase again during the subsequent GA. However, these changes are much smaller as compared with those observed in the ACB group.

\section{Physical activity}

Figure 3 shows the mean standardized scores of patients in both intervention groups separately. Again, a marked increase is observed after EXP and not after GA. After EXP, the increase in movement counts compared with baseline equals a $\mathrm{Z}$-score of about 7 SDs, as compared with only 1.5 after GA.

\section{Pain disability}

For the RDQ, relevant changes are observed when the exposure is effectuated, and not when GA is introduced (Table 4). Overall, RDQ scores decrease from a mean of 17 to a mean of 8 in group $\mathrm{ABC}$ and from 16 to 3 in group $\mathrm{ACB}$, of which the difference largely exceeds the

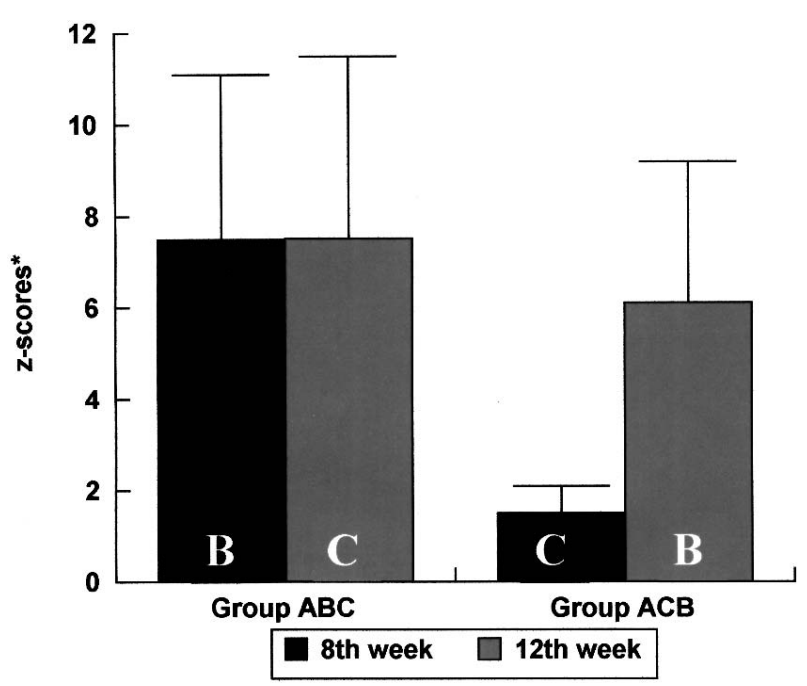

FIG. 3. Mean standardized z-scores (and standard errors) for the activity monitor data after the exposure in vivo (B) and graded activity $(C)$ for treatment groups $A B C$ and $A C B$ during the 8th and 12 th week. ${ }^{*}$ The $z$-score is based on intraperson baseline $(A)$ mean and SD (4th week). 
preset criterion of 5. One patient in the treatment group ACB suffered an acute pain attack at the end of the exposure treatment and had an elevated RDQ score after treatment. The decrease in functional disability remained at follow-up.

\section{DISCUSSION}

The aim of this study was to examine the effectiveness of a cognitive-behavioral EXP treatment as compared with GA in reducing pain-related fears, pain catastrophizing, and pain disability in patients with chronic low back pain reporting substantial fear of movement/(re)injury. Six consecutive such patients who were referred for outpatient behavioral rehabilitation and reported substantial fear of movement/(re)injury were included. A replicated single-case crossover design was applied in which chronically disabled patients were randomly assigned to one of two interventions, which both included EXP and usual GA, but in a reversed order.

Both the time series analyses on the daily measures and preassessments/postassessments showed that compared with a nontreatment baseline period and a GA program, the individually tailored EXP treatment was superior in decreasing levels of fear of movement/(re)injury, fear of pain, and pain catastrophizing. There was an overall improvement in self-reported disability after EXP, suggesting that reductions of pain-related fear generalized to an improvement of functional ability in daily life. Last but not least, the treatment gains were intact at the 1-year follow-up, supporting the robustness of the intervention. Because the experimental design did not include washout periods between the different treatment components, carry-over effects likely occurred. Indeed, when exposure was followed by the GA, the improvements remained stable, which is also consistent with the favorable 1-year follow-up results.

What can be said about the possible mediators of treatment effects? The treatment duration did not include aerobic fitness training and was much too short to produce significant increases in muscle strength. The abrupt changes in the daily measures are suggestive of cognitive changes, such as a reduction in catastrophizing, rather than some kind of habituation. Although the exposure was provided during a period of 3 weeks, the reduction of fear of movement/(re)injury was achieved within fewer than three exposure sessions. Such abrupt changes are more characteristic of insight learning rather than the usual gradual progression of trial-and-error learning. ${ }^{46}$

In our study, the presentation of the rationale at the start of the exposure might have contributed to this insight. Many patients reported that, for the first time, they received a credible rationale for their current level of disability. One way of sorting out this issue is to separate the educational part from the EXP. However, it should be reiterated that the exposure treatment included behavioral tests during which catastrophic beliefs and misinterpretations were challenged. On the basis of the theoretical literature on extinction and fear processes, we hypothesize that the actual experience with or the exposure to the feared situation is likely to produce the greatest changes. ${ }^{47}$ Of particular interest is that all improvements remained after 1 year, suggesting that extinction of fear generalized to situations and movements outside the treatment setting. This is remarkable because there is growing evidence that exposure cannot simply be equated with unlearning. ${ }^{27}$

In a laboratory setting, Goubert et al. ${ }^{48}$ showed that in patients with chronic low back pain, exposure to one movement (bending forward) did not generalize toward another, dissimilar movement (straight leg-raising). The conclusion that the authors made was that during exposure, patients appear to learn exceptions to the rule rather than a fundamental change of that rule. Research findings on exposure in anxiety disorders suggest that generalization and maintenance can be enhanced by a number of measures, including the provision of exposures to the full variety of contexts and natural settings in which fear has been experienced ${ }^{49}$ ample variation of different stimuli during the exposure, ${ }^{50}$ and the application of an exposure over a longer period of time rather than for a limited number of weeks. ${ }^{51}$

It is plausible that in our study generalization was facilitated by the repeated exposure to essential and individually identified stimuli, as measured with PHODA. The finding that activity monitor data follow the same picture as the self-reported measures further supports the assumption that treatment gains produced during the exposure to activities typical of the treatment setting do generalize to the home setting and in the absence of therapists.

Of interest is that current pain intensity levels were also affected by the EXP treatment, especially in one treatment condition (ACB). Such changes are not so common in behavioral treatments for chronic low back pain. Consistent with experimental studies on the role of attention and pain-related fear, ${ }^{52,53}$ successful EXP treatment also resulted in decreases of pain vigilance. This finding corroborates the idea that the most important function of anxiety is the early detection of potentially threatening situations. Our study seems to provide preliminary evidence for a process in which the reduction of the threat value of previously fear-eliciting stimuli (in casu physical activity) also produced an attentional redirection away from pain and bodily sensations. It is likely that the decrease in pain intensity in treatment group 
ACB was mediated by this attentional redirection, because the changes in PVAQ were largest in this group.

Future time series analyses, perhaps with more sensitive repeated measures and smaller time intervals, looking at lagged correlations will be needed to reveal the association of changes in fear of movement/(re)injury and subsequent changes in pain vigilance, pain, and disability.

The EXP treatment evaluated in this study is somewhat contrary to other pain management approaches such as activity pacing, relaxation, and back schools. Some of these interventions even encourage patients to restrict their activity level or certain movements. Our patients, whose thorough medical examinations revealed no specific back disease, were given the unambiguous message that there was no reason for the restriction of usual daily activities. The firm ergonomic advice about lifting, carrying, and sitting that often is provided in the so-called back schools-conveying the message that activities are safe only when performed in an ergonomically correct way-can best be omitted for fearful patients undergoing an EXP procedure. Such advice may be interpreted as a warning that if the instructions are not followed as suggested, the feared catastrophe may occur.

Of course, this does not mean that patients can be exposed to any kind of stimulus. All stimuli used in the exposure procedure should be reasonable and safe for anyone, be chosen with respect to the final treatment goals, always be modeled first by the therapist, and be negotiated with the patient before each exposure session. In rare instances in which fear of movement is considered by the treatment team as an adaptive strategy, EXP will be restricted to those movements that are considered helpful and safe enough for that particular patient.

There are a number of caveats to be considered. First, this study is limited in that it included only six patients. However, a single-case experimental design was chosen with appropriate time series statistical analyses. Because in the crossover design all patients received both interventions, long-term differential effects could not be established. Replication studies in the form of a randomized controlled trial with larger samples and long-term follow-up measurements are warranted.

Second, we decided to exclude from the GA program those physical activities that were placed above 50 on the PHODA fear hierarchy, to avoid contamination between the two treatments. However, it is quite possible that if these activities were included in the GA the differences between treatments would have been smaller. On the other hand, the primary purpose of the GA is not to reduce fears but to gradually increase activity levels despite pain, with use of operant learning principles such as the provision of ample positive reinforcement when individual quotas are met.

Third, there is possible confounding with ongoing treatment. It is possible that elements of the ongoing rehabilitation program moderated the effects of the EXP treatment. For example, relaxation and pacing techniques could make one more responsive to the exposure treatment. Conversely, one can argue that this moderation affected not only the exposure but also the GA program, which is also a behavioral treatment. We recently conducted a similar experiment in which the EXP was provided solely, without any other rehabilitation ingredients. ${ }^{28}$ The results are quite similar to those of the current study, suggesting that contamination bias is likely to be minimal.

This study is one of the rare chronic pain studies using a single-subject experimental design. In 1991, Jensen and colleagues were already calling for such designs because they are "uniquely suited to understanding an individual's coping process over time" $\left({ }^{54}\right.$ [p. 280]). Fortunately, process-oriented research is now receiving much more attention. ${ }^{55,56}$ What can be said about the generalizability of the results to patients other than those included in the single-case experimental design? Although within single-case demonstrations with one or a few subjects it is, by definition, not possible to assess generality across subjects, a few comments are pertinent here.

First, interventions that produce dramatic effects are likely to be more generalizable than those with weaker effects, ${ }^{57}$ and this appears to be true here. Using time series analysis, we have demonstrated that the changes could not be attributed to chance. Second, generalizability may be derived from the fact that replications of six different patients show consistently similar results in this study and in other studies. ${ }^{23,28,58}$ The extent of the generality of the findings is of course a function of the number of changes in conditions included in the replications. So far, it seems justifiable to generalize the results to other patients with back pain who report substantial fear of movement/(re)injury.

It may be desirable in future studies to increase the number of differences between the experiments and, for example, test the intervention in patients with other musculoskeletal pain problems such as whiplash, fibromyalgia, or shoulder pain. Another question to be answered is whether the EXP also works for patients who are less fearful (for example, those who have TSK scores within the 37-40 range). However, to evaluate interactions between treatments and subjects' characteristics, it might be more appropriate to use between-group factorial designs. Such a randomized controlled study also might shed light on whether the long-term effects are specific 
to the EXP. We are currently preparing such a study that also includes cost-effectiveness analyses.

Acknowledgments: The authors thank Herman Mulder, Noel Dortu, and the staff of the Department of Pain Rehabilitation of the Hoensbroek Rehabilitation Center, for contributing to the clinical care of the patients, and to Peter Muris and an anonymous reviewer, for their comments on an earlier version of the manuscript.

\section{REFERENCES}

1. Asmundson GJ, Norton PJ, Norton GR. Beyond pain: the role of fear and avoidance in chronicity. Clin Psychol Rev 1999;19:97119.

2. Linton SJ, Buer N, Vlaeyen JWS, et al. Are fear-avoidance beliefs related to the inception of an episode of back pain: a prospective study. Psychol Health 2000;14:1051-9.

3. McNeil DW, Au AR, Zvolensky MJ, et al. Fear of pain in orofacial pain patients. Pain 2001;89:245-52.

4. Vlaeyen JW, Kole-Snijders AM, Boeren RG, et al. Fear of movement/(re)injury in chronic low back pain and its relation to behavioral performance. Pain 1995;62:363-72.

5. Vlaeyen JW, Linton SJ. Fear-avoidance and its consequences in chronic musculoskeletal pain: a state of the art. Pain 2000;85: $317-32$.

6. Lethem J, Slade PD, Troup JD, et al. Outline of a fear-avoidance model of exaggerated pain perception: I. Behav Res Ther 1983;21: 401-8.

7. Waddell G, Newton M, Henderson I, et al. A Fear-Avoidance Beliefs Questionnaire (FABQ) and the role of fear-avoidance beliefs in chronic low back pain and disability. Pain 1993;52:157-68.

8. Al-Obaidi SM, Nelson RM, Al-Awadhi S, et al. The role of anticipation and fear of pain in the persistence of avoidance behavior in patients with chronic low back pain. Spine 2000;25:1126-31.

9. Burns JW, Mullen JT, Higdon LJ, et al. Validity of the pain anxiety symptoms scale (PASS): prediction of physical capacity variables. Pain 2000;84:247-52.

10. Crombez G, Vlaeyen JW, Heuts PH, et al. Pain-related fear is more disabling than pain itself: evidence on the role of pain-related fear in chronic back pain disability. Pain 1999;80:329-39.

11. Crombez G, Vervaet L, Baeyens F, et al. Do pain expectancies cause pain in chronic low back patients: a clinical investigation. Behav Res Ther 1996;34:919-25.

12. Asmundson GJ, Norton GR, Allerdings MD. Fear and avoidance in dysfunctional chronic back pain patients. Pain 1997;69:231-6.

13. Vlaeyen JWS, Kole Snijders AMJ, Rotteveel AM, et al. The role of fear of movement/(re)injury in pain disability. J Occup Rehab 1995;5:235-52.

14. Bortz WM. The disuse syndrome. West J Med 1984;141:691-4.

15. Wagenmakers AJ, Coakley JH, Edwards RH. The metabolic consequences of reduced habitual activities in patients with muscle pain and disease. Ergonomics 1988;31:1519-27.

16. Watson P, Booker CK, Main CJ, et al. Surface electromyography in the identification of chronic low back pain patients: the development of the flexion relaxation ratio. Clin Biomech 1997;12: $165-71$.

17. Romano JM, Turner JA. Chronic pain and depression: does the evidence support a relationship? Psychol Bull 1985;97:18-34.

18. McQuade KJ, Turner JA, Buchner DM. Physical fitness and chronic low back pain: an analysis of the relationships among fitness, functional limitations, and depression. Clin Orthop 1988:198-204.

19. Wolpe J. Psychotherapy by reciprocal inhibition. Stanford, CA: Stanford University Press, 1958.

20. Craske MG, Rowe MK. A comparison of behavioral and cognitive treatments of phobias. In: Davey GCL, ed. Phobias: a handbook of theory, research and treatment. Chichester: Wiley \& Sons, 1997:247-80.

21. Philips HC. Avoidance behavior and its role in sustaining chronic pain. Behav Res Ther 1987;25:273-9.

22. de Jong JR, Vlaeyen JWS, Geilen MJ, et al. De angst voor bewegen: geleidelijke exposure in vivo bij chronische lage rugpijn [The fear of movement: graded exposure in vivo in chronic low back pain]. Directieve Therapie 2000;20:143-61.

23. Vlaeyen JW, de Jong J, Geilen M, et al. Graded exposure in vivo in the treatment of pain-related fear: a replicated single-case experimental design in four patients with chronic low back pain. Behav Res Ther 2001;39:151-66.

24. Lindstrom I, Ohlund C, Eek C, et al. The effect of graded activity on patients with subacute low back pain: a randomized prospective clinical study with an operant-conditioning behavioral approach Phys Ther 1992;72:279-90; discussion 291-3.

25. Fordyce WE, Brockway JA, Bergman JA, et al. Acute back pain: a control-group comparison of behavioral vs traditional management methods. J Behav Med 1986;9:127-40.

26. Vlaeyen JW, Groenman NH, Thomassen J, et al. A behavioral treatment of sitting and standing intolerance in a patient with chronic low back pain [see comments]. Clin J Pain 1989;5:233-7.

27. Bouton ME. Context and ambiguity in the extinction of emotional learning: implications for exposure therapy. Behav Res Ther 1988 26:137-49.

28. Vlaeyen JWS, de Jong JR, Onghena P, et al. Can pain-related fear be reduced: the application of cognitive-behavioral exposure in vivo. Pain Res Manage 2002; in press.

29. Morley S. Single case research. In: Parry G, Watts FN, eds. Behavioral and mental health research: a handbook of skills and methods. Erlbaum, UK: Taylor \& Francis, 1996:277-314.

30. Kori SH, Miller RP, Todd DD. Kinesiophobia: a new view of chronic pain behavior. Pain Manage 1990;1:35-43.

31. Arrindell WA, Ettema JHM. Handleiding bij een multidimesnionele psychpathologie-indicator. Lisse: Swets \& Zeitlinger, 1986.

32. Kugler K, Wijn J, Geilen M, et al. The photograph series of daily activities (PHODA). CD-ROM version 1.0. Heerlen, The Netherlands: Institute for Rehabilitation Research and School for Physiotherapy, 1999.

33. Fordyce WE. Behavioral methods for chronic pain and illness. St. Louis: Mosby, 1976.

34. Kole-Snijders AM, Vlaeyen JW, Goossens ME, et al. Chronic low-back pain: what does cognitive coping skills training add to operant behavioral treatment? Results of a randomized clinical trial. J Consult Clin Psychol 1999;67:931-44.

35. Vlaeyen JWS, De Jong J, Geilen M, et al. Graded exposure in vivo for pain-related fear: the case of chronic musculoskeletal pain. In: Rice A, Warfield C, Justins D, et al., eds. Handbook of clinical pain management. London: Arnold; in press.

36. Borkovec TD, Nau SD. Credibility of analogue therapy rationales. J Behav Ther Exper Psychol 1972;3:257-60.

37. McCracken LM, Zayfert C, Gross RT. The pain anxiety symptoms scale: development and validation of a scale to measure fear of pain. Pain 1992;50:67-73.

38. Sullivan MJL, Bishop SR, Pivik J. The pain catastrophizing scale: development and validation. Psychol Assess 1995;7:524-32.

39. Goubert L, Crombez G, Vlaeyen JWS, et al. De Tampa schaal voor Kinesiofobie: Psychometrische karakteristieken en normering [The Tampa scale for kinesophobia: psychometric properties and norms]. Gedrag en Gezondheid, 2000;28:54-62.

40. McCracken LM. "Attention" to pain in persons with chronic pain: a behavioral approach. Behav Ther 1997;28:271-81.

41. Roelofs J, Peters ML, Vlaeyen JWS. Dutch version of the Pain Vigilance and Awareness Questionnaire: validity and reliability in a pain-free population. Behavior Res Ther; in press.

42. Bussmann JB, van de Laar YM, Neeleman MP, et al. Ambulatory accelerometry to quantify motor behavior in patients after failed back surgery: a validation study. Pain 1998;74:153-61.

43. Roland M, Morris R. A study of the natural history of back pain: 
I. Development of a reliable and sensitive measure of disability in low back pain. Spine 1983;8:141-4.

44. Deyo RA, Battie M, Beurskens AJ, et al. Outcome measures for low back pain research: a proposal for standardized use [erratum appears in Spine. 1999;24:418]. Spine 1998;23:2003-13.

45. Stratford PW, Binkley J, Solomon P, et al. Defining the minimum level of detectable change for the Roland-Morris questionnaire. Phys Ther 1996;76:359-65; discussion 366-8.

46. Rachman S, Whittal M. Fast, slow and sudden reductions in fear. Behav Res Ther 1989;27:613-20.

47. Davey GCL. A conditioning model of phobias. In: Davey GCL, ed. Phobias: a handbook of theory, research and treatment. Chichester: John Wiley and Sons, 1997:301-22.

48. Goubert L, Francken G, Crombez G, et al. Exposure to physical movement in chronic back pain patients: no evidence for generalization across different movements. Behav Res Ther 2002;40: $415-29$.

49. Mineka S, Mystkowski JL, Hladek D, et al. The effects of changing contexts on return of fear following exposure therapy for spider fear. J Consult Clin Psychol 1999;67:599-604.

50. Rowe MK, Craske MG. Effects of varied-stimulus exposure training on fear reduction and return of fear. Behav Res Ther 1998;36: $719-34$.
51. Rowe MK, Craske MG. Effects of an expanding-spaced vs massed exposure schedule on fear reduction and return of fear. Behav Res Ther 1998;36:701-17.

52. Asmundson GJ, Kuperos JL, Norton GR. Do patients with chronic pain selectively attend to pain-related information: preliminary evidence for the mediating role of fear. Pain 1997;72:27-32.

53. Peters ML, Vlaeyen JWS, Kunnen AMW. Is pain-related fear a predictor of somatosensory hypervigilance in chronic low back pain patients? Behav Res Ther 2002;40:85-103.

54. Jensen MP, Turner JA, Romano JM, et al. Coping with chronic pain: a critical review of the literature. Pain 1991;47:249-83.

55. Keefe FJ, Affleck G, Lefebvre JC, et al. Pain coping strategies and coping efficacy in rheumatoid arthritis: a daily process analysis. Pain 1997;69:35-42.

56. Peters ML, Sorbi MJ, Kruise DA, et al. Electronic diary assessment of pain, disability and psychological adaptation in patients differing in duration of pain. Pain 2000;84:181-92.

57. Kazdin AE. Single-case research designs. Oxford: Oxford University Press, 1982.

58. Linton SJ, Overmeer T, Janson M, et al. Graded in vivo exposure treatment of fear-avoidant pain patients with functional disability: a case study. Cognitive Behav Ther 2002; in press. 